\title{
Study on the Soil Fertilizing Activities of Salt Tolerant Yeast Isolates
}

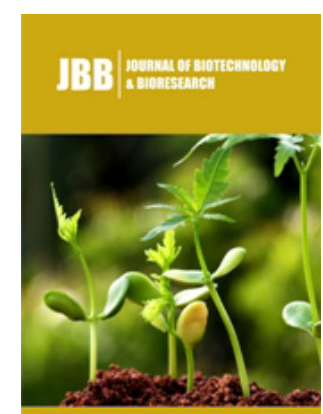

*Corresponding author: May Thet Nwe, Department of Biotechnology Research, Myanmar

Submission: 眥 March 19, 2019

Published: 眥April 04, 2019

Volume 1 - Issue 5

How to cite this article: May Thet Nwe, Zaw Ko Latt, San San Yu, Sabae Thant and Nwe Nwe Aung. Study on the Soil Fertilizing Activities of Salt Tolerant Yeast Isolates. J Biotech Biores.1(5). JBB.000522.2019.

Copyright@ May Thet Nwe, This article is distributed under the terms of the Creative Commons Attribution 4.0 International License, which permits unrestricted use and redistribution provided that the original author and source are credited.

\author{
May Thet Nwe, Zaw Ko Latt*, San San Yu, Sabae Thant and Nwe Nwe Aung \\ Biotechnology Research Department, Myanmar.
}

\begin{abstract}
Twelve salt tolerant yeasts were isolated from various salted soils from Thanlyin Township, Yangon Region. The salt tolerant activity was determined by plate screening in different salt concentrations. Among them, four yeast isolates which have the highest salt tolerance activity (3-14\%) were selected for further study. These four isolates grow well in temperature from $15^{\circ} \mathrm{C}$ to $45^{\circ} \mathrm{C}$ and $\mathrm{pH}$ range $3-9$. The fertilizing activities of yeast isolates such as nitrogen fixing activity was measured by Indophenol method, phosphorus solubilizing activity and potassium decomposing activity were determined by spectrometry and Flame Photometry respectively. Among four isolates, the best two isolates were chosen and used as biofertilizer for rice cultivation in salted soil.
\end{abstract}

Keywords: Salt tolerant yeasts; Nitrogen fixation; Phosphate solubilization; Potassium decomposition; Rice cultivation

\section{Introduction}

Several environmental factors adversely affect plant growth and development and final yield performance of a crop. Drought, Salinity, Nutrient imbalances (Including Mineral Toxicities and deficiencies) and extremes of temperature are among the major environmental constraints to crop productivity worldwide. Salinity is the most serious water quality problem in agriculture. Water salinity is an environmental stress factor that inhibits growth and yield of crop plants in many regions of the world. Improving salinity and tolerance of crop plants using biofertilization has been an important but largely unfulfilled aim of modern agricultural development [1]. Soil salinity is an increasing threat for agriculture [2] and it stresses plants in two ways. High concentrations of salts in the soil make it harder for roots to extract water, and high concentrations of salts within the plant can be toxic. Salts on the outside of roots have an immediate effect on cell growth and associated metabolism; toxic concentrations of salts take time to accumulate inside plants before they affect plant function [3].

Salinity affects almost all aspects of plant development, including germination, vegetative growth and reproductive development. Soil salinity imposes ion toxicity, osmotic stress, nutrient (N, Ca, K, P, Fe, and Zn) deficiency and oxidative stress on plants. Salinity also indirectly limits plant productivity through its adverse effects on the growth of beneficial and symbiotic microbes. High salt concentrations in soil impose osmotic stress and thus limit water uptake from soil. Plants, like all other living things need food for their growth and development [4]. They are classified into two categories which are macronutrient and micronutrient depending on the quantity requirement. NPK (nitrogen, phosphorus, potassium) are primary macronutrients element which are needed in large amounts while copper, boron and iron are example of micronutrients that are needed in only very small amount or microquantity [5]. Although Earth's atmosphere contains $78 \%$ nitrogen gas $\left(\mathrm{N}_{2}\right)$, most organisms cannot directly use this resource due to the stability of the compound.

Plants, animals and microorganisms can die of nitrogen deficiency, surrounded by $\mathrm{N}_{2}$ they cannot use. All organisms use the ammonia $\left(\mathrm{NH}_{3}\right)$ form of nitrogen to manufacture amino acids, proteins, nucleic acids and other nitrogen-containing components necessary for life [6]. Nitrogen is present in all living organisms, in proteins, nucleic acids and other molecules. It typically makes up around $4 \%$ of the dry weight of plant matter. Nitrogen is required for cellular synthesis of enzymes, proteins, chlorophyll, DNA and RNA, and is therefore important in plant growth and production of food and feed. Inadequate supply of available $\mathrm{N}$ frequently results in plants that have slow growth, depressed protein levels, poor yield of low-quality 
produce, and inefficient water use [7]. Phosphorus (P) is a major growth-limiting nutrient that can be made biologically available. Root development, stalk and stem strength, flower and seed formation, crop maturity and production, $\mathrm{N}$-fixation in legumes, crop quality, and resistance to plant diseases are the attributes associated with phosphorus nutrition [5].

Although phosphorus uptake by plants is less compared to nitrogen and potassium, normal plant growth cannot be achieved without it [8]. The concentration of soluble Phosphorus (P) in tropical soil is usually very low; Phosphorus is only available in micro molar quantities or less [9]. Deficiency of soil P is one of the most important chemical factors restricting plant growth in soils. The over fertilization of P leads to pollution due to soil erosion and runoff water containing large amounts of soluble phosphorus. Some microorganisms are known to be involved in the solubilization of insoluble phosphate [10]. Potassium is also vital for animal and human nutrition, and thus healthy fruits, vegetables and grains must have adequate levels of $\mathrm{K}$ [11]. Potassium is used to build cellulose and aids in photosynthesis by the formation of a chlorophyll precursor. Potassium deficiency may result in higher risk of pathogens, wilting, chlorosis, brown spotting, and higher chances of damage from frost and heat.

Primary nutrients NPK which are utilized in the large amounts by crops are commonly found in blended fertilizers nowadays [5]. Based on the production process, the fertilizers can be roughly categorized into three types: chemical, organic and biofertilizer. The use of chemical fertilizer or organic fertilizer has its advantages and disadvantages in the context of nutrient supply, crop growth and environmental quality [12]. The excessive use of chemical fertilizers has generated several environmental problems including the greenhouse effect, ozone layer depletion and acidification of water. These problems can be tackled by use of biofertilizers [13]. Soil microbes are of great importance in cycling nutrients such as Carbon (C), Nitrogen (N), Phosphorus (P), and Sulphur (S).

Not only do they control the forms of these elements. The use of living bacteria (Biofertilizer) accelerates mineralization of organic residues in soil, therefore makes the nutrients more available. At the same time due to the effect of living bacteria from biofertilizer, the uptake of heavy metals decreases [14]. Biological fertilizer based on yeasts utilizes metabolic activities of living yeasts to convert raw materials, such as atmospheric nitrogen and phosphorous and potassium minerals, into plant nutrients, the conversion and release of such nutrients by the yeast cells is regulated in part by the nutrient content of the soil. The main aim of this paper is to apply salt tolerant yeasts as biofertilizer in salt affected soil.

\section{Materials and Methods}

\section{Isolation and screening of salt tolerant activities of yeast isolates}

Soil samples were collected from various salt affected soils from Thanlyin Township, Yangon Region, Myanmar. Yeasts were isolated on Peptone Yeast Glucose (PYG) medium by using serial dilution method. After one day incubation, different morphologies of yeast colonies were checked, selected and purified. Salt tolerant activity of isolates was firstly investigated by plate screening method on PYG medium containing different sodium chloride $(\mathrm{NaCl})$ concentrations such as $0 \%, 2 \%, 4 \%, 6 \%, 8 \%, 10 \%, 12 \%$ and $14 \%$ respectively. From observation of the growth condition, the best salt tolerant isolates were selected for further studies.

\section{Characterization of isolated salt tolerant yeasts}

Among twelve salt tolerant yeasts, only four isolated yeasts which have the highest salt tolerant activities were characterized by colonial and microscopic morphology, sugar fermentation and assimilation patterns, and some biochemical tests.

\section{Growth of yeasts at different temperature and $\mathrm{pH}$}

Single colony of isolated yeast was streaked on PYG agar medium and incubated at $15^{\circ} \mathrm{C}, 20^{\circ} \mathrm{C}, 25^{\circ} \mathrm{C}, 30^{\circ} \mathrm{C}, 35^{\circ} \mathrm{C}, 40{ }^{\circ} \mathrm{C}$ and $45{ }^{\circ} \mathrm{C}$ respectively. After 48 hours incubation, the growth of yeast strains was observed. Single colony of yeast isolates was inoculated in PYG broth adjusted with different pH levels (3, 5, 7 and 9) and incubated at $30{ }^{\circ} \mathrm{C}$ for two days. After two days incubation, the colony numbers were counted by serial dilution method.

\section{Ammonia accumulation, phosphate solubilization and potassium decomposing}

Plant growth promoting activities of yeast strains were studied such as phosphate solubilization, $\mathrm{NH}_{3}$ production, siderophore production and Indole Acetic Acid (IAA) production etc. In this study, ammonia accumulation, phosphate solubilization and potassium decomposing activities were studied. Accumulated ammonia concentration in nitrogen free culture broth was detected by Indophenol method. Phosphate solubilizing activities was measured by UV-vis spectrophotometer at $830 \mathrm{~nm}$ using $\mathrm{Ca}_{3}\left(\mathrm{PO}_{4}\right)_{2}$ as substrate and potassium decomposing activity was measured by Flame Photometry using K-Mica as substrate.

\section{Cultivation of rice plants in salted soil}

The cultivated soil was sterilized and filled into the chambers. The rice seeds were prepared for seedlings. The seed bed of rice plants was prepared, and the seeds were placed one-centimeter soil depth in the rows and covered thin layer of soil. After seedlings, the thirty days old healthy seedlings were transplanted in the above chambers with sterile soil. Each chamber contained 3 kinds of rice plants. After 45 days, the salt concentrations of the soils in the chambers were adjusted with $\mathrm{NaCl}$ solution. Five treatments were applied with four replicates at 10 days interval. The treatments used were: T1- Chemical fertilizer, T2- Salted water only, T3Isolate Y3, T4- Isolate Y4, T5- Isolate Y3+Y4. After thirty days of transplantation, the rice plants in chambers from all treatments were harvested. After harvesting, the yield parameters such as plant height, effective tiller, panicle length and 100 grain weight were determined.

\section{Determination of chlorophyll index}

The chlorophyll index was determined by measuring the colour of leaf blade with chlorophyll meter (SPAD-502 Plus). 


\section{Result and Discussion}

\section{Isolation and screening of salt tolerant activities of yeast isolates}

Twelve strains of soil yeasts were isolated from various salt affected soils and screened for their salt tolerant activity at $0 \%$,
$2 \%, 4 \%, 6 \%, 8 \%, 10 \%, 12 \%$ and $14 \%$ of $\mathrm{NaCl}$ concentrations. The highest salt tolerant four isolates (Y1, Y2, Y3, Y4) were selected for further activities. These four isolates grew well up to $10 \%$ and their growth became poor at 12 and $14 \% \mathrm{NaCl}$. On screening with other salts $\left(\mathrm{KCl}, \mathrm{CaCl}_{2}, \mathrm{MgCl}_{2}\right)$, their growth was good at different concentrations of $\mathrm{KCl}$ and $\mathrm{CaCl}_{2}$, but poor to remaining one.

\section{Characterization of salt tolerant yeasts}

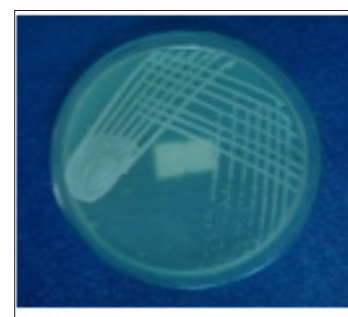

Y1

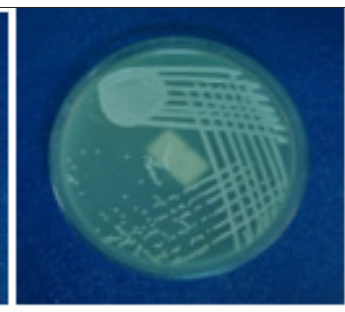

Y2

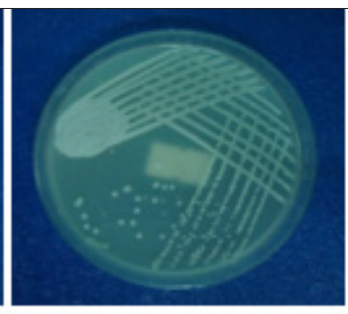

Y3

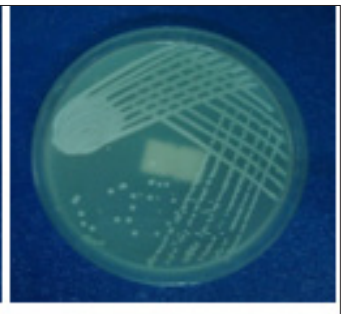

$\mathrm{Y} 4$

Figure 1: Colonial Morphology of Isolates Y1, Y2, Y3 and Y4 on PYG Medium.

In conventional characterization of yeast strains, colonial and microscopic morphology, assimilation and fermentation patterns on various carbohydrate sources are important. So, the selected isolates were characterized by morphological and biochemical methods. In morphological characteristics, color, shape, texture and surface of colony on PYG media were examined in Figure 1. The color of all isolates was cream color. The physiological and biochemical tests of isolates were carried out by using different carbon sources for assimilation and fermentation activities. In this study, although all isolates could ferment sugars such as fructose, maltose, glucose, sucrose and dextrose, they could not ferment xylose. Isolates Y2 and Y3 could not also ferment lactose. All isolates could utilize alcohol such as ethanol and glycerol, but they could not utilize methanol (Figure 1).

\section{Growth of yeasts at different temperature and $\mathrm{pH}$}

The isolates $\mathrm{Y} 1, \mathrm{Y} 2, \mathrm{Y} 3$ and $\mathrm{Y} 4$ grew well in the temperature adjusted with $15{ }^{\circ} \mathrm{C}$ to $45^{\circ} \mathrm{C}$ Table 1 and also grew well in the $\mathrm{pH}$ range of 3 to 9 (Figure 2) (Table 1).

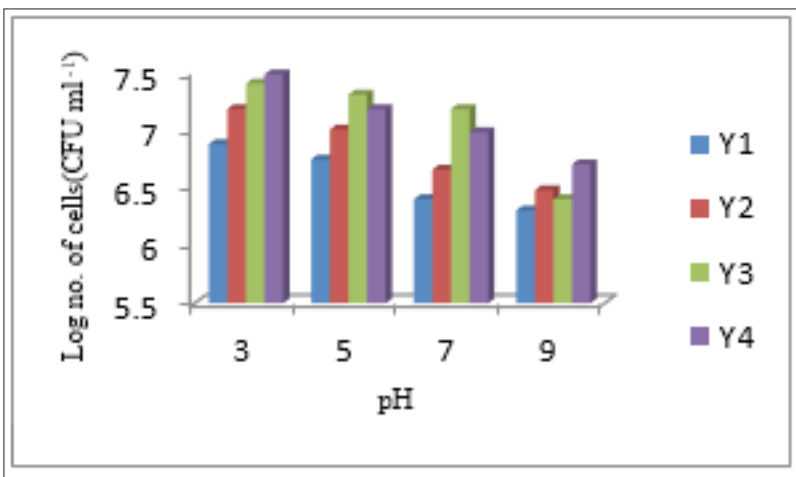

\section{$\mathrm{CFU}=$ colony forming unit}

Figure 2: Growth Rate of Isolates on PYG Media with Different pH.

Table 1: Growth condition of isolates on different temperature.

\begin{tabular}{|c|c|c|c|c|c|c|}
\hline \multirow{2}{*}{ Isolates } & \multicolumn{5}{|c|}{ Temperature } \\
\cline { 2 - 6 } & $\mathbf{1 5}{ }^{\circ} \mathbf{C}$ & $\mathbf{2 0}{ }^{\circ} \mathbf{C}$ & $\mathbf{2 5}{ }^{\circ} \mathbf{C}$ & $\mathbf{3 0}{ }^{\circ} \mathbf{C}$ & $\mathbf{3 5}^{\circ} \mathbf{C}$ & Growth \\
\hline Y1 & Growth & Growth & Growth & Growth & Growth & Growth \\
\hline Y2 & Growth & Growth & Growth & Growth & Growth & Growth \\
\hline Y3 & Growth & Growth & Growth & Growth & Growth \\
\hline Y4 & Growth & Growth & Growth & Growth & Growth \\
\hline
\end{tabular}




\section{Screening of fertilizing activity}

Determination of nitrogen fixing activity: When $\mathrm{N}_{2}-$ fixing activity was detected by Indophenol method, accumulated ammonium concentration was very low in all isolates. In $\mathrm{N}_{2}$ - fixing activity, $\mathrm{Y} 1$ was given the highest $\mathrm{N}_{2}$ - fixing activity without $\mathrm{NaCl}$ concentration in 9 days incubation period. $\mathrm{Y} 2$ also gave the highest $\mathrm{N}_{2}$ - fixing activity in 9 days incubation period containing $0 \%$ and $2 \% \mathrm{NaCl}$ concentration. Y2 also showed the fixing activity in 12 days incubation period containing $8 \%, 10 \%, 12 \%$ and $14 \% \mathrm{NaCl}$ concentrations Figure 3. Y3 showed the highest $\mathrm{N}_{2}$ - fixing activity in 9 days incubation period without $\mathrm{NaCl}$. In 6 days and 9 days, Y3 gave no distinct $\mathrm{N}_{2}$ - fixing activity in all $\mathrm{NaCl}$ concentrations. The fixing activity of $\mathrm{Y} 4$, isolate indicated the $\mathrm{N}_{2}$ - fixing activity in 9 days incubation period in nitrogen free media containing $0 \%, 2 \%, 4 \%$, $6 \%, 8 \%, 10 \%, 12 \%$ and $14 \% \mathrm{NaCl}$ concentrations. Among all four isolates, $\mathrm{Y} 4$ gave the highest $\mathrm{N}_{2}$ - fixing activity containing $8 \% \mathrm{NaCl}$ concentration in 9 days (Figure $3 \& 4$ ).

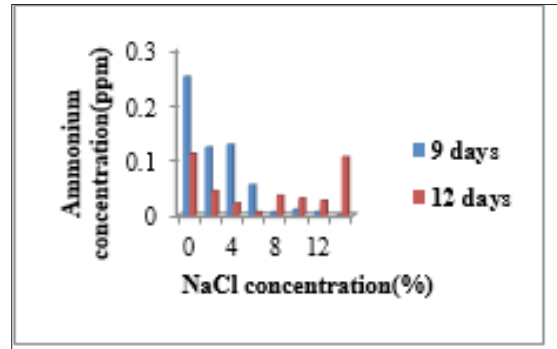

(a) Y1

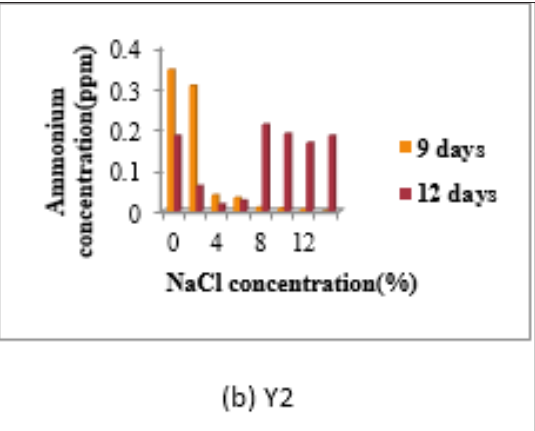

Figure 3: Determination of Ammonium Concentration of Isolates (a) Y1 and (b) Y2.

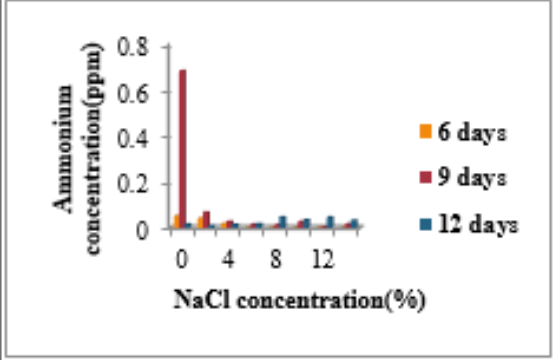

(a) Y3

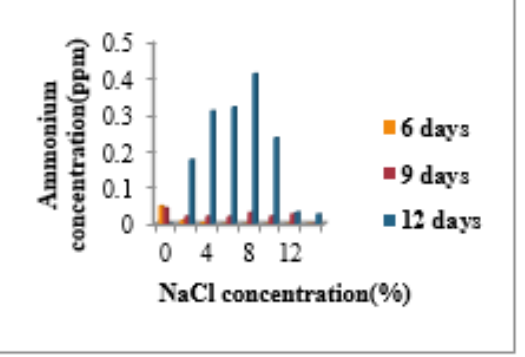

(b) Y4

Figure 4: Determination of Ammonium Concentration of Isolates (a) Y3 and (b) Y4.

\section{Quantitative measurement of phosphate} solubilization activity: In phosphate solubilizing activity, activities of all isolates were high in $0 \%$ and $2 \% \mathrm{NaCl}$ concentration. Y1 was given the highest $P$ solubilizing activities in 6 days incubation periods containing different $\mathrm{NaCl}$ concentrations such as $0 \%, 2 \%$, $4 \%, 6 \%, 8 \%$ and $10 \%$. For isolate $\mathrm{Y} 2$, the highest solubilizing activity was shown in 6 days incubation period of media containing $0 \%$, $2 \%$ and $4 \% \mathrm{NaCl}$ concentrations. In media containing $6 \%, 8 \%$ and
$10 \% \mathrm{NaCl}$ concentrations, the solubilizing activities were higher in 3 days incubation period than 6 days and 9 days incubation periods Figure 5. The solubilizing activity of $\mathrm{Y} 3$ and $\mathrm{Y} 4$, the highest activities was indicated in 6 days incubation period than 3 days and 9 days in all media containing $0 \%$ to $10 \% \mathrm{NaCl}$ concentrations. According to this data, the highest solubilizing was shown in 6 days incubation period in all four isolates. When $\mathrm{NaCl}$ concentration is high, the soluble P content is low (Figure 5 \& 6).

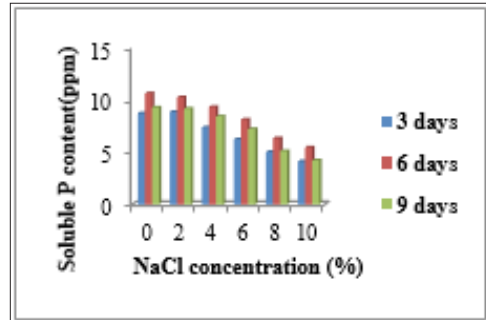

(a) Y1

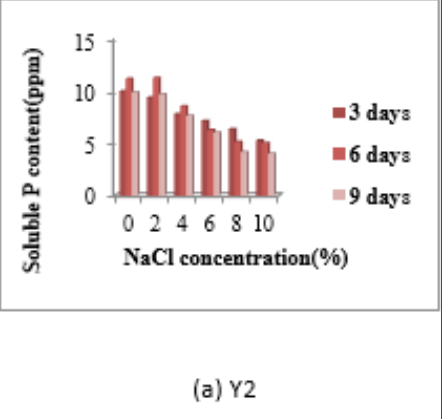

Figure 5: Quantitative Measurement of P Solubilizing Activities of Isolates (a) Y1 and (b) Y2. 


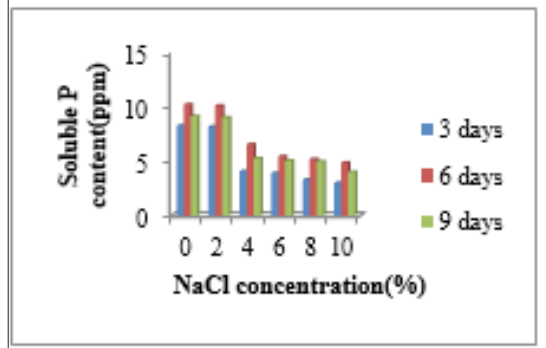

(a) Y3

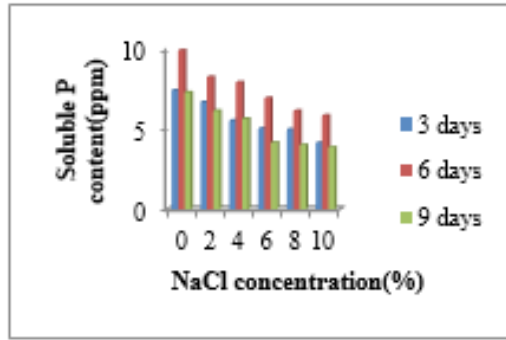

(b) Y4

Figure 6: Quantitative Measurement of P Solubilizing Activities of Isolates (a) Y3 and (b) Y4.

Potassium decomposition activity of yeast isolates: In determination of potassium decomposing activities, although isolates did not give clear zone formation on plate screening, they released soluble $\mathrm{K}$ in potassium decomposing yeast broth adding
$0.12 \%$ Mica as substrate. $8 \mathrm{ppm}$ of soluble $\mathrm{K}$ content for isolates Y1 and Y 3 and 9ppm for isolates Y2 and Y4 were released when measured by flame photometry method (Figure 7).

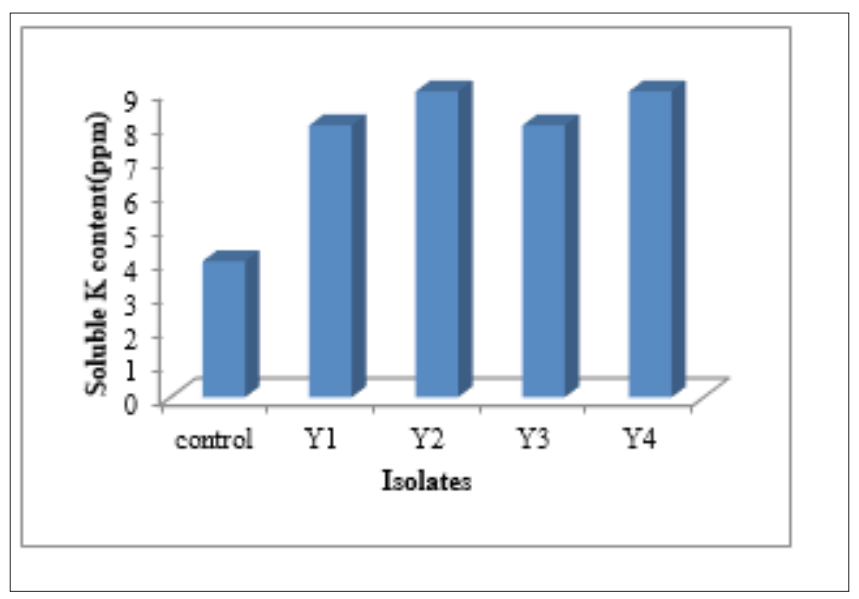

Figure 7: Determination of Soluble K Content.

Nutritional value of cultivated soils: Salted soil samples were treated using selected isolates and analytical data of cultivated soil compared between before and after treatments were measured. In soil analytical data Table 2, the nutritional values of cultivated soil treated with isolates $\mathrm{Y} 3$ and $\mathrm{Y} 4$ gave better results than untreated cultivated soil (Table 2).

Table 2: Analytical data of cultivated soil.

\begin{tabular}{|c|c|c|c|c|c|c|c|}
\hline \multirow{2}{*}{ Soil Samples } & \multirow{2}{*}{$\begin{array}{l}\text { Mois- } \\
\text { ture \% }\end{array}$} & \multirow{2}{*}{$\begin{array}{c}\text { pH Soil Water } \\
1: 2.5\end{array}$} & \multirow{2}{*}{$\begin{array}{c}\text { Electrical } \\
\text { Conductivity } \\
\text { ms } / \mathbf{c m}\end{array}$} & \multirow{2}{*}{ Total N \% } & \multirow{2}{*}{$\begin{array}{c}\begin{array}{c}\text { Exchangeable Cations } \\
\text { meq/100g }\end{array} \\
\mathrm{K}^{+}\end{array}$} & \multicolumn{2}{|c|}{ Available Nutrients } \\
\hline & & & & & & P ppm & $\mathrm{K}_{2} \mathrm{O} \mathrm{mg} / 100 \mathrm{~g}$ \\
\hline Untreated soil & 1.87 & 7.93 & - & 0.16 & 0.65 & 8.56 & 30.58 \\
\hline $\begin{array}{l}\text { Chemical fertil- } \\
\text { izer }\end{array}$ & 2.67 & 8.18 & 0.1 & 0.2 & 0.79 & 27.54 & 36.99 \\
\hline Salted water only & 2.86 & 8.32 & 1.1 & 0.23 & 0.79 & 18.95 & 37.07 \\
\hline Isolate Y3 & 2.61 & 8.15 & 1.07 & 0.2 & 0.83 & 25.05 & 38.8 \\
\hline Isolate Y4 & 2.84 & 8.13 & 1.04 & 0.22 & 0.78 & 20.98 & 36.41 \\
\hline Isolate Y3 + Y4 & 2.6 & 8.11 & 0.97 & 0.23 & 0.81 & 24.64 & 38.19 \\
\hline
\end{tabular}

Determination of chlorophyll index: According to the chlorophyll data, rice plants treated with yeast isolates Y3 and Y4

were produced more chlorophyll content than untreated plants (Figure 8). 


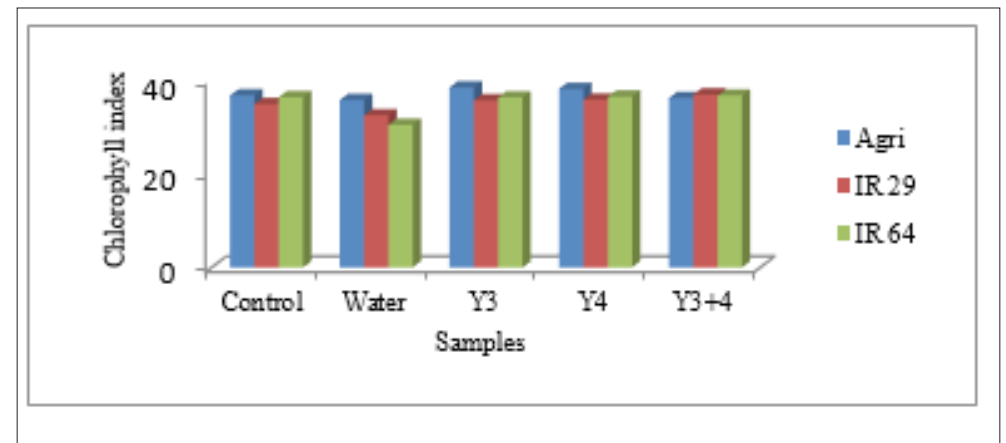

Figure 8: Chlorophyll Index of Rice Plants in Salt Affected Soil..

Effect of selected salt tolerant yeasts on salted soil cultivation: One of the objectives of this paper is to study the effects of selected salt tolerant yeast isolates on salted soil rice cultivation Figure $9 \& 10$. The other parameters such as plant height, effective tillers, and length of panicles and 100 grains weight were measured. In cultivation of IR 29, treatments with isolates Y3 was given the best parameters than the other treatments Table 3. And then IR 64, treatments with isolates Y4 was shown better data than the other treatments (Figure $9 \& 10$ ); (Table $3 \& 4$ ).

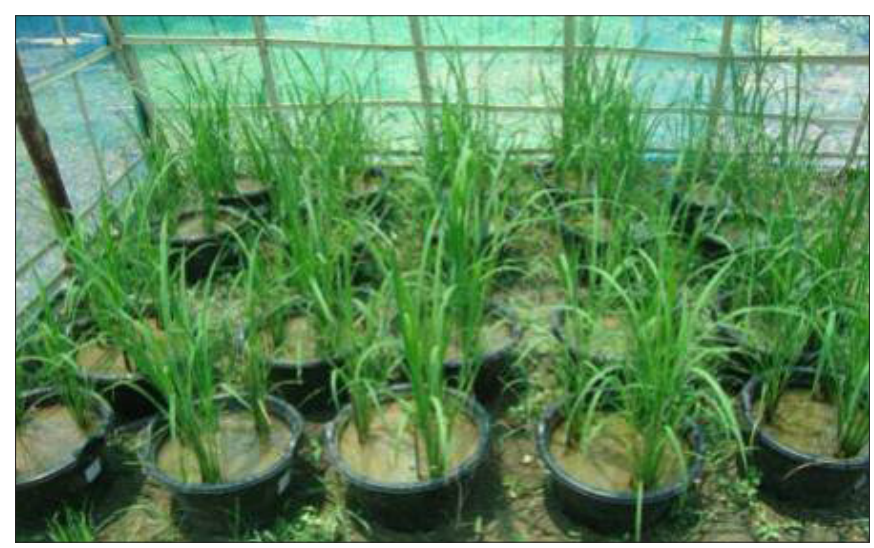

Figure 9: Cultivation of Rice Plants in Salted Soil.

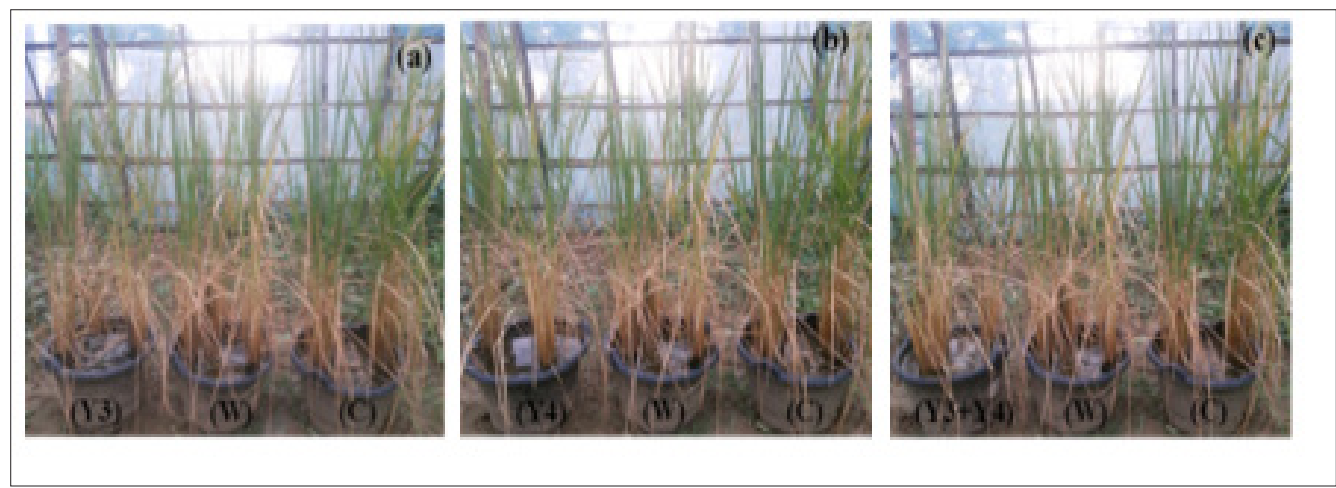

Figure 10: Cultivation of Rice Plants in Salted Soil Treated with Salt Tolerance Yeasts (a)Y3 (b)Y4 (c) Y3+Y4..

Table 3: Effects of isolates on rice var. IR 29 cultivation in salted soil.

\begin{tabular}{|c|c|c|c|}
\hline Treatment & Plant Height $(\mathbf{c m})$ & Effective Tiller & Panicle Length (cm) \\
\hline Chemical fertilizer & $112.5 \pm 4.93$ & $11.25 \pm 2.31$ & $24.75 \pm 1.71$ \\
\hline Salted water only & $103.00 \pm 2.16$ & $9.25 \pm 1.26$ & $24.75 \pm 1.71$ \\
\hline Isolate Y3 & $103.75 \pm 3.30$ & $9.75 \pm 1.5$ & $25.75 \pm 1.26$ \\
\hline Isolate Y4 & $98.00 \pm 1.63$ & $8.5 \pm 1$ & $24.75 \pm 1.71$ \\
\hline Isolate Y3+Y4 & $101.75 \pm 4.79$ & $9.5 \pm 1$ & $23.5 \pm 1.73$ \\
\hline
\end{tabular}


Table 4: Effects of isolates on rice var. IR 64 cultivation in salted soil.

\begin{tabular}{|c|c|c|c|c|}
\hline Treatment & Plant Height $\mathbf{( c m )}$ & Effective Tiller & Panicle Length (cm) & 100 Grains Weights (g) \\
\hline Chemical fertilizer & $84.75 \pm 9.64$ & $6.5 \pm 1.73$ & $19.63 \pm 2.29$ & - \\
\hline Salted water only & $86.00 \pm 4.69$ & $6.75 \pm 0.96$ & $20.75 \pm 3.86$ & 1.46 \\
\hline Isolate Y3 & $82.25 \pm 5.74$ & $5.00 \pm 1.95$ & $20.5 \pm 1$ & 0.99 \\
\hline Isolate Y4 & $79.75 \pm 11.21$ & $6.5 \pm 1$ & $20.00 \pm 5.35$ & 1 \\
\hline Isolate Y3+Y4 & $81.00 \pm 2.16$ & $5.5 \pm 4.04$ & $15.00 \pm 10.09$ & 0.74 \\
\hline
\end{tabular}

\section{Conclusion}

Although twelve yeast strains were isolated, only four strains were selected depending on their salt tolerant activity. These four isolates tolerate up to $14 \% \mathrm{NaCl}$ concentration. All four isolates could grow well at temperature $15{ }^{\circ} \mathrm{C}$ to $45^{\circ} \mathrm{C}$ and in the $\mathrm{pH}$ range from 3 to 9 . On detection of fertilizing activities, selected four yeast isolates possessed $\mathrm{N}_{2}$ fixing, $\mathrm{P}$ solubilizing and $\mathrm{K}$ decomposing activities. So, the salt tolerant yeasts could be used as biofertilizer in salted soil cultivation. In cultivation of rice, treated rice plants with salt tolerant yeasts produced more chlorophyll content than untreated rice plants. After cultivation, the resulting data treated with isolates $\mathrm{Y} 3$ and $\mathrm{Y} 4$ gave better results in plant parameters and soil analytical data.

\section{Acknowledgement}

I would like to thank Director, Biotechnology Research Department, Kayaks', for allowing to conduct this research work and helpful supporting of this research work.

\section{References}

1. Hamdia MA, Shaddad MAK (2010) Salt tolerance of crop plants. Botany department, Faculty of Science, EI Minia University, Egypt.

2. Chen JH (2006) The combined use of chemical and organic fertilizers and/or biofertilizer for crop growth and soil fertility. In: International workshop on sustained management of the soil-rhizosphere system for efficient crop production and fertilizer use. Land Development Department, Thailand, pp.1-11.

3. Rana M, Mark T (2008) Mechanism of Salinity Tolerance. Annu Rev Biol 59: 651-681.
4. Khiat SHA (2006) Effect of cyanobacteria as a soil conditioner and biofertilizer on growth and some biochemical characteristics of tomato (Lycopersiconesculentum L.) Seedlings. Microbiology (Algae), Special Publication, King Saud University, Saudi Arabia, pp. 1-4.

5. Ahmad AK, Ghulam J, Mohammad SA, Syed MS (2009) Phosphorus solubilizing bacteria: Occurrence, mechanisms and their role in crop production. J Agric Biol Sci 1(1): 48-58.

6. Lindemann WC, Glover CR (2008) Nitrogen fixation by legumes. Electronic Distribution, pp. 1-4.

7. Rifat H, Safdar AUA, Rabia K, Iftikhar A (2010) Soil beneficial bacteria and their role in plant growth promotion: A Review. Ann Microbiol 60(4): 579-598.

8. Bin ZAA (2009) Growth optimization of potassium solubilizing bacteria isolated from biofertilizer: A thesis. Faculty of Mechanical Engineering, University Malaysia Pahang, Malaysia.

9. Henri F, Dieudonne N, Annette D, Lamina D, Wolfgang M, et al. (2006) Occurrence and functioning of phosphate solubilizing microorganisms from oil palm tree (Elaeisguineensis) rhizosphere in Cameroon. African Journal of Biotechnology 5(24): 2450-2460.

10. Hong JS, Geun TP, Mi C, Moon SH (2006) Solubilization of insoluble inorganic phosphates by a novel salt- and $\mathrm{pH}$-tolerant pantoeaagglomerans R-42 isolated from soybean rhizosphere. Bioresource Technology 97(2): 204-210.

11. Brian J (2007) Forms and Functions of Essential Plant Nutrient, Virgenia cooperative extension, pp. 1-4.

12. Jen HC (2006) The combined use of chemical and organic fertilizers and/or biofertilizer for crop growth and soil fertility. 16(20): 1-10.

13. Saadatnia H, Riahi H (2009) Cyanobacteria from paddy fields in Iran as a biofertilizer in rice plants. Plant Soil Environ 55 (5): 207-212.

14. Levai L, Szilvia V (2008) Can wood ash and biofertilizer play a role in organic agriculture? Agronomski Glasnic 70(3): 263-271. 